\title{
Efektivitas Model Flipped Classroom Menggunakan Video Pembelajaran Matematika terhadap Pemahaman Konsep
}

\author{
M. Eko Arif Saputra1, Mujib' \\ 1Universitas Islam Negeri Raden Intan Lampung. Jalan Endro Suratmin, Sukarame, Bandar \\ Lampung 35133, Indonesia. \\ *Corresponding Author. E-mail: ekoarif1995@gmail.com
}

Received : 19-03-2018; Revised : 13-05-2018; Accepted : 30-05-2018

\begin{abstract}
Abstrak
Model Flipped Classroom adalah model dimana dalam proses belajar mengajar tidak seperti pada umumnya, yaitu dalam proses belajarnya siswa mempelajari materi pelajaran dirumah sebelum kelas dimulai dan kegiatan belajar mengajar dikelas berupa mengerjakan tugas, berdiskusi tentang materi atau masalah yang belum dipahami siswa. Tujuan dari penelitian ini adalah untuk mengetahui pengaruh model Flipped Classroom terhadap kemampuan pemahaman konsep matematis. Jenis penelitian ini menggunakan penelitian Quasi Experiment Design dan Teknik sampling yang digunakan adalah metode Probability Sampling dengan tehnik Random Sampling. Uji hipotesis yang digunakan dalam penelitian ini yaitu uji-t. Hasil penelitian uji statistik menunjukkan bahwa nilai dari $t_{\text {hitung }}$ berdasarkan perhitungan yang diperoleh $t_{\text {hitung }}=12.868$, dan $t_{\text {tabel }}=1.668$ sehingga $t_{\text {hitung }}>t_{\text {tabel }}$, dengan taraf nyata 0,05 dengan kata lain dapat disimpulkan bahwa pemahaman konsep matematis siswa yang diterarapkan model Flipped Classroom lebih baik dari kemampuan pemahaman konsep yang diterapkan dengan metode ceramah.
\end{abstract}

Kata Kunci: Flipped Classroom, Kemampuan Pemahaman Konsep Matematis.

\begin{abstract}
Flipped Classroom model is a model where in the learning process is not like in general, that is in the learning process students learn the subject matter at home before the class begins and teaching and learning activities in the class in the form of tasks, discussion about materials or problems that students have not understood. The purpose of this study is to determine the effect of Flipped Classroom model on the ability of understanding mathematical concepts. This research type used Quasi Experiment Design research and sampling technique used is Probability Sampling method with Random Sampling technique. Hypothesis test used in this research is $t$-test. The result of statistical test shows that the value of t_hitung based on the calculation obtained t_hitung $=12.868$, and t_tabel $=1.668$ so t_hitung $>$ t_tabel, with a real level of 0.05 in other words it can be concluded that the understanding of mathematical concepts of students who expected model Flipped Classroom is better than the ability to understand concepts that are applied with lecture methods
\end{abstract} Keywords: Ability to Understand Mathematical Concepts; Flipped Classroom.

\section{PENDAHULUAN}

Mempelajari matematika tidak hanya memahami konsepnya saja atau prosedurnya saja, akan tetapi banyak hal yang dapat muncul dari hasil proses pembelajaran matematika (Masykur, Nofrizal, \& Syazali, 2017; Widyastuti, 2015). Menyangkut dengan penjelasan tersebut maka perlu suatu pembelajaran yang terstruktur dalam pembelajaran matematika dengan tujuan meningkatkan pemahaman konsep dalam pembelajaran matematika itu sendiri.

Kemampuan pemahaman

konsep sangat penting bagi peserta didik, karena konsep matematika yang 
satu dengan yang lain saling berkaitan sehingga untuk mempelajarinya harus runtun dan berkesinambungan (Farida, 2015; Haryani, 2017). Namun kenyataannya kemampuan pemahanan konsep peserta didik masih belum menggembirakan. Kondisi ini didukung oleh pernyataan yang diungkapkan oleh penelitian sebelumnya bahwa tingkat pemahaman konsep peserta didik masih sangat rendah. Tidak hanya peserta didik di sekolah, permasalahan kemampuan pemahaman konsep matematis juga terjadi pada mahasiswa seperti yang telah dijelaskan oleh (Karim, 2011; Sudarman \& Vahlia, 2016). Permasalahan ini disebabkan oleh model pembelajaran yang kurang tepat dalam pembelajaran matemati (Netriwati, 2016; Purwasih, 2015; Yusri, 2016). Diduga model Flipped Classroom mampu mengatasi permasalahan pada pemahaman konsep matematika

Flipped Classroom adalah proses belajarnya siswa mempelajari materi pelajaran dirumah sebelum kelas dimulai dan kegiatan belajar mengajar dikelas berupa mengerjakan tugas, berdiskusi tentang materi atau masalah yang belum dipahami siswa (Yulietri \& Mulyoto, 2015). Hasil dari penelitian terdahulu mengungkapkan bahwa pembelajaran model Flipped Classroom dapat meningkatkan hasil belajar peserta didik. Selain itu penelitian yang dilakukan oleh (Yulietri \& Mulyoto, 2015) menghasilkan bahwa model Flipped Classroom dapat meningkatkan rasa tanggung jawab dan meningkatkan kemampuan berfikir kritis peserta didik dalam belajar matematika. Sedangkan (Damayanti \& Sutama, 2016; Rahman, Armiati, Akmil, \& Rizal, 2012) dalam penelitiannya mengungkapkan bahwa pengaruh yang besar terhadap tingginya kemandirian belajar peserta didik dengan pembelajaran menggunakan model Flipped Classroom terdapat. Karena pada dasarnya konsep model Flipped Classroom adalah pembelajaran yang dilakukan di kelas namun dilakukan oleh peserta dirumah sehingga peserta didik dapat lebih belajar mandiri. Berdasarkan penelitian terdahulu yang telah dipaparkan di atas, maka dalam mengatasi permasalahan kemampuan pemahaman konsep yang ada penulis tertarik melakukan sebuah penelitian menggunakan model flipped classroom.

Penelitian ini akan berbeda dengan penelitian sebelumnya yaitu pada bantuan yang digunakan. Jika pada penelitian yang telah dijelaskan di atas model Flipped Classroom disinergikan dengan sebuah metode pembelajaran, tetapi pada penelitian ini penulis menggunakan bantuan sebuah video pembelajaran dengan tujuan agar dapat meningkatkan pemahaman konsep matematika peserta didik.

\section{METODE PENELITIAN}

Dalam penelitian ini, penulis menggunakan metode penelitian eksperimen karena penulis akan mencari perbedaan treatment (perlakuan) tertentu. Jenis metode eksperimen yang digunakan adalah Quasy Experimental Design. Teknik 
Desimal, 1 (2), 2018 - 175

M. Eko Arif Saputra, Mujib

sampling yang digunakan adalah metode Probability Sampling dengan tehnik Random Sampling. Instrumen yang digunakan dalam penelitian ini adalah instrumen tes (tes kemampuan pemahaman konsep matamatika). Teknik analisis data dalam pengujian hipotesis adalah sebagai berikut (Novalia \& Syazali, 2014):

1. Uji normalitas

Uji normalitas dengan menggunakan metode Lilifors, dengan rumus:

$L_{\text {hitung }}=\operatorname{Max}|f(z)-S(z)|, L_{\text {tabel }}=$ $L_{(\alpha, n)}$

Dengan hipotesis

$\mathrm{H}_{0}$ : data mengikuti sebaran normal

$\mathrm{H}_{1}$ : data tidak mengikuti sebaran

normal

Kriteria uji

Jika $L_{\text {hitung }} \leq$

$L_{\text {tabel }}$ maka $H_{0}$ diterima.

Dengan taraf signifikan $\alpha=0,05$

2. Uji Homogenitas

Uji homogenitas dengan menggunakan uji kesamaan 2 varians. rumus yang digunakan dalam mencari $\mathrm{F}_{\text {hitung }}$ :

$F=\frac{\text { Varians } T \text { erbesar }}{\text { Varians Terkecil }}$

Kriteria uji,

jika $F_{\text {hitung }} \leq: F_{\text {tabel, }}$

maka $H_{0}$ adalah Homogen

$H_{0}: \sigma_{1}=\sigma_{2}$, bahwa $H_{0}$ diterima atau sempel berasal dari populasi yang memiliki varians sama (Data homogen).

$H_{1}: \sigma_{1} \neq \sigma_{2}, H_{1}$ ditolak atau sempel berasal dari populasi yang memiliki varians tidak sama (Data tidak homogen)

\section{Uji Hipotesis}

untuk mencari uji-t digunakan rumus sebagai berikut: $t=\frac{\text { Varians Terbesar }}{\operatorname{sgab} \sqrt{\frac{1}{n_{1}}+\frac{1}{n_{2}}}}$,

dimana

$S_{g a b}=\frac{\bar{X} 1-\bar{X} 2}{\sqrt{\frac{\left(n_{1}-1\right) s_{1}^{2}+\left(n_{2}-1\right) s_{1}^{2}}{n_{1}+n_{2}-2}}}$

Keterangan :

$\overline{\mathrm{X}}_{1}=$ Nilai rata-rata kemampuan pemahaman konsep matematis kelas eksperimen

$\overline{\mathrm{X}}_{2}=$ Nilai rata-rata kemampuan pemahaman konsep matematis kelas kontrol

$n_{1}=$ Banyaknya peserta didik kelas eksperimen

$n_{2}=$ Banyaknya peserta didik kelas control

$s_{1}^{2}=$ Varians data kelompok eksperimen

$s_{2}^{2}=$ Varians data kelompok control

$s_{\text {gab }}=$ Simpangan baku kedua kelompok

Adapun langkah-langkah pengujian hipotesis ini sebagai berikut:

$H_{o}$ : Kemampuan pemahaman konsep matematis siswa yang diterapkan model Flipped Classroom lebih baik dari kemampuan pemahaman konsep yang diterapkan dengan metode ceramah.

$H_{1}$ : Kemampuan pemahaman konsep matematis siswa yang diterapkan model Flipped Classroom tidak lebih baik dari kemampuan pemahaman konsep yang diterapkan dengan metode ceramah.

Dengan Kriteria Uji:

jika $\left|t_{\text {hitung }}\right| \geq t_{\text {tabel }}$, maka $H_{0 \text { ditolak }}$

(Uji Dua Pihak) dengan taraf signifikan $\alpha=0,05$.

\section{HASIL DAN PEMBAHASAN}

Hasil dari Penerapan strategi flipped classroom dan konvensional diterima dengan baik oleh siswa karena pada dasarnya siswa 
mempunyai kemampuan matematika yang baik. Namun terbatasnya frekuensi peneliti dalam menerapkan strategi flipped classroom dikelas eksperimen maka pengaruh penggunaan strategi flipped classroom tidak tampak signifikan pada pencapaian kemampuan kognitif siswa. Selain itu fakta yang ditemukan peneliti yaitu mengingat bahwa siswa dapat melihat video ceramah pada computer mereka sendiri, kondisi dimana mereka kemungkinan melihat video ceramah menjadi pembelajaran yang tidak efektif (misalnya siswa bisa melihat video sambil mendengarkan musik) dan siswa tidak menonton atau memahami video karena itu mereka tidak siap atau belum cukup siap untuk kegiatan tatap muka.

Setelah data kemampuan pemahaman Konsep matematis peserta didik terkumpul baik dari kedua kelas eksperimen maupun dari kelas kontrol diperoleh maka diperoleh:

Tabel 1. Deskripsi Data Kemampuan Pemahaman Konsep Matematis

\begin{tabular}{lllccc}
\multicolumn{1}{c}{ Kelas } & $\mathbf{X}_{\text {maks }}$ & $\mathbf{X}_{\text {min }}$ & \multicolumn{3}{c}{ Ukuran Tendensi sentral } \\
& & & $\overline{\boldsymbol{x}}$ & $\mathbf{M e}$ & Mo \\
Eksperimen & 95 & 35 & 62,44 & 60 & 60 \\
Kontrol & 77 & 20 & 50,19 & 47 & 40 \\
\hline
\end{tabular}

Setelah dilaksanakan pembelajaran, pada kelas Eksperimen dan Kelas Kontrol dilakukan evaluasi akhir untuk mengetahui kemampuan pemahaman Konsep Matematis peserta didik sebagai pengumpulan data hasil evaluasi akhir diperoleh bahwa pada kelas eksperimen berjumlah 36 peserta didik dengan tes soal essai pada kemampuan pemahaman konsep matematis didapat nilai terbesar 95 dan nilai terkecil 35, nilai tengah (Me) 60 , nilai terbanyak yang didapat peserta didik (Mo) adalah 60 dan rata-rata nilai peserta didik adalah 62,44. Sedangkan pada kelas Kontrol yang berjumlah 31 peserta didik dengan hasil tes kemampuan pemahaman konsep matematis didapat nilai terbesar 77 dan nilai terkecil 20, nilai rata-rata yang diperoleh peserta didik adalah 50,19, dengan Median 47 serta nilai yang sering muncul adalah 40. Berdasarkan hal ini dapat disimpulkan bahwa kemampuan pemahaman konsep peserta didik kelas eksperimen (mendapat model Flipped Classroom) lebih baik dari peserta didik kelas Kontrol (Mendapat metode ceramah)

Selanjutnya dilakukan analisis uji asumsi dengan uji normalitas kemampuan pemahaman konsep matematis siswa pada kelas eksperimen dengan hasil skor kelas eksperimen sebesar 62,444 dengan $\boldsymbol{L}_{\text {hitung }}=$ , 0,1117 dan $L_{\text {tabel }}=\mathbf{0 . 1 4 5 4}$ hal ini menunjukan bahwa $\boldsymbol{L}_{\text {hitung }}<\boldsymbol{L}_{\text {tabel }}$ sehingga dapat disimpulkan data berdistribusi normal. Dan kelas control adalah sekor kelas kontrol sebesar 50,1935 dengan $\boldsymbol{L}_{\text {hitung }}=\mathbf{0 , 1 0 1 6 \mathrm { dan }}$

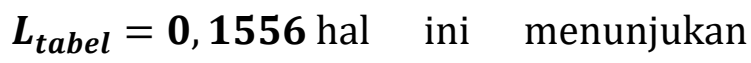
bahwa $\boldsymbol{L}_{\text {hitung }}<\boldsymbol{L}_{\text {tabel }}$ sehingga dapat disimpulkan data berdistribusi normal. Berikut hasil rekapitulasi perhitungan uji normalitas Pemahaman Konsep matematis pada kelas eksperimen dan kelas kontrol. 
Tabel 2. Hasil Perhitungan Uji Normalitas

\begin{tabular}{ccccc}
\hline Kelas & Jumlah Sempel & $\boldsymbol{L}_{\text {hitung }}\left(L_{(\alpha, n)}\right)$ & $\boldsymbol{L}_{\text {tabel }}$ & Keterangan \\
Eksperimen & 36 & 0,1117 & 0.1454 & Normal \\
Kontrol & 31 & 0,1016 & 0,1556 & Normal \\
\hline
\end{tabular}

Berdasarkan perhitungan hasil uji coba normalitas Kemampuan Pemahaman Konsep matematis pada kelas eksperimen dan kelas kontrol dengan taraf sigifikansi $\alpha=0,05$, diperolah bahwa nilai dari $L_{\text {hitung }}$ dari setiap kelompok kurang dari $L_{\text {tabel }}$ sehingga hipotesis nol dari setiap kelompok diterima. Dapat disimpulkan bahwa data yang diperoleh dari setiap kelompok berasal dari populasi yang berdistribusi normal. Uji Kesamaan Dua Varians kemampuan Pemahaman Konsep Matematis. Untuk mengetahui apakah kedua skor memiliki karakter yang sama atau berbeda maka diperlukan uji F. Pengujian variansi ini yaitu membandingkan varians terbesar dan varians terkecil. Jika $F_{\text {hitung }} \leq$ $F_{\text {tabel }}\left(\sigma_{1}, \sigma_{2}\right)$ didapat dari distribusi dengan peluang $\frac{1}{2} \alpha$ sedangkan derajat kebebasan $\sigma_{1}\left(n_{1}-1\right)$ dan $\sigma_{2}\left(n_{2}-2\right)$ masing-masing sesuai dengan $d k$ pembilang dan $d k$ penyebut. Hasil pengujian varians dengan taraf signifikan $\alpha=0,05$ dapat dilihat pada Tabel 3 .

Tabel 3. Hasil Perhitungan Uji Kesamaan Dua Varians

\begin{tabular}{cccccc}
\hline Kelas & Jumlah Sempel & Varians & $\boldsymbol{F}_{\text {hitung }}$ & $\boldsymbol{F}_{\text {tabel }}$ & Keterangan \\
Eksperimen & 36 & 63,454 & 1,204 & 1,810 & Homogen \\
Kontrol & 31 & 218,694 & & & \\
\hline
\end{tabular}

Berdasarkan Tabel 3. Hasil sama. Untuk menguji perbedaan perhitungan skor Kemampuan Kemampuan Pemahaman konsep Pemahaman konsep matematis matematis peserta didik digunakan diperoleh $\quad F_{\text {hitung }}=1,204$ dan rumus uji-t, karena data yang diperoleh $F_{\text {tabel }}=1,810$. Menunjukan bahwa berdistribusi normal dan memiliki nilai $F_{\text {hitung }}<F_{\text {tabel }}$ dengan hal ini dapat varians sama. Hasil perhitungan dapat disimpulkan bahwa $H_{0}$ diterima atau dilihat pada Tabel 4. berikut ini: sampel berasal dari populasi yang memiliki varians

Tabel 4. Hasil Perhitungan Uji

\begin{tabular}{lccccc}
\hline Kelas & JumlahSempel & Rata-Rata $(\boldsymbol{x})$ & $\boldsymbol{t}_{\boldsymbol{t a b e l}}\left(\boldsymbol{t}_{\boldsymbol{a}, \boldsymbol{d b}}\right)$ & $\boldsymbol{t}_{\boldsymbol{h i t u n g}}$ & Keterangan \\
Eksperimen & 36 & 62,444 & 1,668 & 12,868 & Terima $_{0}$ \\
Kontrol & 31 & 50,193 & & & \\
\hline
\end{tabular}

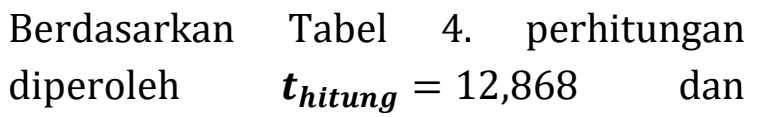

$\boldsymbol{t}_{\text {tabel }}=1,668$ sehingga $\boldsymbol{t}_{\text {hitung }}>\boldsymbol{t}_{\text {tabel }}$, yang berarti $\mathrm{H}_{0}$ ditolak yang berarti. Kemampuan Pemahaman konsep dengan 
model Flipped Classroom menggunakan video pembelajaran lebih baik dari pada kemampuan pemahaman konsep menggunakan metode ceramah.

Berdasarkan hal ini dapat disimpulkan bahwa ada pengaruh kepada peserta didik yang mendapat perlakuan model pembelajaran Flipped Classroom menggunakan video pembelajaran Hal ini disebabkan karena model Flipped Classroom menggunakan video pembelajaran lebih banyak memberikan kesempatan peserta didik untuk belajar dimanapun dan kapanpun. Video tersebut ddapat diulang-ulang hingga ia benar-benar paham materi.

Hasil penelitian ini sama dengan hasil penelitian yang dilakukan oleh Widyatia $d k k$, dengan hasil yang dinyatakan bahwa pemahaman konsep matematis siswa lebih baik dengan menggunakan model Flipped Classroom (Pharamita \& Muchtar, 2016; Ridha, Setyosari, \& Kuswandi, 2016; Prayitno \& Masduki, 2015)

\section{SIMPULAN DAN SARAN}

Berdasarkan teori dan didukung oleh dengan hasil analisis dan pengolahan data serta mengacu pada perumusan masalah yang telah diuraikan, maka dapat disimpulkan bahwa: terdapat perbedaan kemampuan pemahaman konsep matematis peserta didik dengan penerapan model Flipped Classroom menggunakan video pembelajaran. Selanjutnya kemampuan pemahaman konsep matematis peserta didik

dengan model Flipped Classroom dengan menggunakan video pembelajaran lebih baik daripada metode pembelajaran ceramah.

Berdasarkan kesimpulan penulis menyarankan agar pendidik menggunakan model Flipped Classroom menggunakan video pembelajaran matematika untuk meningkatkan Kemampuan Pemahaman Konsep Matematis peserta didik

\section{DAFTAR PUSTAKA}

Damayanti, H. N., \& Sutama, S. (2016). Efektivitas Flipped Classroom Terhadap Sikap dan Ketrampilan Belajar Matematika di SMK. Manajemen Pendidikan, 11(1), 2-7.

Farida, F. (2015). Mengembangkan Kemampuan Pemahaman Konsep Peserta Didik Melalui Pembelajaran Berbasis VCD. Al-Jabar: Jurnal Pendidikan Matematika, 6(1), 25-32. https://doi.org/10.24042/ajpm.v6i 1.54

Haryani, Y. (2017). Penggunaan Model Discovery Learning terhadap Peningkatkan Kemampuan Koneksi dan Komunikasi Matematik. AlJabar: Jurnal Pendidikan Matematika, 8(1), 43-52. https://doi.org/10.24042/ajpm.v8i 1.963

Karim, A. (2011). Penerapan metode penemuan terbimbing dalam pembelajaran matematika untuk meningkatkan pemahaman konsep dan kemampuan berpikir kritis siswa sekolah dasar. Jurnal Pendidikan.

Masykur, R., Nofrizal, N., \& Syazali, M. (2017). Pengembangan Media Pembelajaran Matematika dengan Macromedia Flash. Al-Jabar: Jurnal Pendidikan Matematika, 8(2), 177185.

Netriwati, N. (2016). Analisis Kemampuan Mahasiswa dalam Pemecahkan Masalah Matematis menurut Teori Polya. Al-Jabar: Jurnal Pendidikan Matematika, 7(2), 181-190. https://doi.org/10.24042/ajpm.v7i 2.32

Novalia, N., \& Syazali, M. (2014). Olah Data Penelitian Pendidikan. Bandar 
Lampung: Anugrah Utama Rahaja.

Purwasih, R. (2015). Peningkatan Kemampuan Pemahaman Matematis dan Self Confidence Siswa MTS di Kota Cimahi Melalui Model Pembelajaran Inkuiri Terbimbing. Didaktik, 9(1), 16-25.

Rahman, A., Armiati, A., Akmil, A., \& Rizal, Y. (2012). Implementasi CTL dalam Meningkatkan Pemahaman Konsep Matematika Siswa. Jurnal Pendidikan Matematika, 1(1), 24-29.

Sudarman, S. W., \& Vahlia, I. (2016). Efektifitas Penggunaan Metode Pembelajaran Quantum Learning terhadap Kemampuan Pemahaman Konsep Matematis Mahasiswa. AlJabar: Jurnal Pendidikan Matematika, 7(2), 275-282. https://doi.org/10.24042/ajpm.v7i 2.42

Widyastuti, R. (2015). Proses Berpikir Siswa dalam Menyelesaikan Masalah Matematika berdasarkan Teori Polya ditinjau dari Adversity Quotient Tipe Climber. Al-Jabar: Jurnal Pendidikan Matematika, 6(2), 183-194.

Yulietri, F., \& Mulyoto, M. (2015). Model Flipped Classroom dan Discovery Learning Pengaruhnya Terhadap Prestasi Belajar Matematika Ditinjau Dari Kemandirian Belajar. Jurnal Teknodika, 13(2).

Yusri, R. (2016). Pengaruh Pendekatan Problem Centered Learning terhadap Kemampuan Pemahaman Konsep Matematis Siswa Kelas X SMA Negeri Kabupaten Solok. PROSIDING, 2(1), 165-171. 